Because it was rarely possible to isolate the common soil fungus Rhizoctonia by this method, a modification of the method devised by Papavizas and Davey ${ }^{3}$ was used instead. Mature lima bean (Phaseolus vulgaris L.) stems were flushed in running tap water for 1-2 min, immersed in a 10 per cent solution of bleaching powder for $30 \mathrm{sec}$, and then washed in sterile water. The stem internodes were then cut into $1 / 8 \mathrm{in}$. segments, and buried in samples of freshly collected cultivated and fallow soils (stored in glass troughs). After incubation at $23^{\circ}-24^{\circ} \mathrm{C}$ for 3 days, the stem segments were washed first in tap water to remove the attached soil particles and then in five changes of sterile water in a Griffin's electric shaker for $2 \mathrm{~min}$. The stem segments were then damp-dried between sheets of sterile blotting paper and transferred to plates of 2 per cent water agar. Any fungal colonies growing out from the stem segment after $24 \mathrm{~h}$ incubation at $23^{\circ}-25^{\circ} \mathrm{C}$ were sub-cultured on PDA plates ${ }^{3}$. In general, because only one small colony appeared after such a short incubation period, one isolation was made from each stem segment.

During June-August 1964, a total of 260 stem segments were plated out for the two soils. The results showed that, whereas 41 per cent of the lima bean stem segments taken from the cultivated soil were colonized by Rhizoctonia, only 2.7 per cent of the segments from the fallow soil were infected. It thus became clear that Rhizoctonia was far more abundant in the cultivated soil than in the fallow soil.

It is tempting to suggest that cultivation of the soil resulted in the build-up of Rhizoctonia but evidence to support this is lacking. Moreover, the pathogenicity of both Rhizoctonia and the other possible pathogenic genera isolated in the previous study ${ }^{1}$ has not been established as yet. There were no serious outbreaks of any soil-borne disease in the intensively cultivated cabbage fields. The reasons for the absence of disease are not known; it is possible, however, that the micro-organism was not pathogenic, or that it was not sufficiently virulent. Unfavourable weather conditions or perhaps resistance of the crop may also have played a part.

Department of Botany,

Myra Chu

University of Hong Kong.

${ }^{1}$ Chu, Myra, and Stephen, R. C. (in preparation).

2 Warcup, J. H., Nature, 166, 117 (1950).

s Papavizas, G. C., and Davey, C. B., Phytopath., 52, 834 (1960).

\section{An Attempt to predetermine the Sex of Calves by Artificial Insemination with Spermatozoa separated by Sedimentation}

BHATTACHARYA ${ }^{1,2}$ has described a method for separating from rabbit semen two fractions of sperm with which he achieved a significant degree of predetermination of sex. He suggested that the separation depends on the tendency of the female producing $X$-sperm to sediment more rapidly than the male-producing $Y$-sperm, when the sperm are rendered immotile by cooling to $1^{\circ} \mathrm{C}$ and then allowed to sink undor the influence of gravity for $12 \mathrm{~h}$ through a column of a viscous egg yolk medium. This communication describes briefly the results of experiments designed to examine the applicability of Bhattacharya's technique to cattle.

Specimens of about $1.5 \mathrm{ml}$. of semen from either Hereford or Friesian bulls were provided by the Cambridge Cattle Breeding Centre. After $24 \mathrm{~h}$ for treatment at Babraham to separate the fast and slowly sedimenting spermatozoa, samples from the top and bottom of the columns were given code numbers and returned to Cam. bridge. For the first series of separations an egg yolk/ glycerine medium (' $A$ ') was used, in conjunction with the glass apparatus described by Bhattacharya ${ }^{2}$. Later separations were carried out in a milk/glycerol medium (' $B$ '), with an apparatus consisting of a stack of stainless steol sheets drilled with holes to form columns which could be fractionated by sliding the sheets sideways. Between November 1964 and July 1965, 411 cows were inseminated with fractionated semen ( $24 \mathrm{~h}$ old), and 191 of them became pregnant, giving a conception rate of 46.5 per cent. A control group of inseminations using untreated semen from the same collections gave 192 pregnancies in 310 cows, a conception rete of 61.9 per cent. The 191 test pregnancies yielded 153 calves of known sex, of which eight were twins; in forty-two cases the sex of the calves was not reported, usually because of sale of the cows before calving. A comparison of the predicted and actual sexes of 139 of these calves is given in Table 1. Fourteen returns (eight males and six females) were excluded from the analysis, either because a non-standard technique was used (for example, medium ' $A$ ', but the stainless steel apparatus), or because sperm counts made after the semen had been dispatched to the inseminators showed that there was doubt whether the samples were the best representative 'top' or 'bottom' fraction. Of the twins, there was one pair of males and one pair of mixed sex in each of the two categories, medium ' $A$ ' predicted female, and medium ' $B$ ' predicted male. In 136 calves of the control group the sex of which was returned, there were sixty-nine males and sixty-seven females.

\begin{tabular}{|c|c|c|c|}
\hline \multirow{5}{*}{$\begin{array}{l}\text { Technique } \\
\text { Medium ' } A \text { ', glass apparatus } \\
\text { Medium ' } B \text { ', s',ainless steel apparatus } \\
\text { Medium ' } B \text { '. d’eep freeze method }\end{array}$} & Predicted sex & \multicolumn{2}{|c|}{ Actual sex } \\
\hline & \multirow{4}{*}{$\begin{array}{l}\text { Male } \\
\text { Female } \\
\text { Male } \\
\text { Female } \\
\text { Female }\end{array}$} & \multirow{4}{*}{$\begin{array}{l}12 \mathrm{M} \\
32 \mathrm{M} \\
12 \mathrm{M} \\
13 \mathrm{M} \\
15 \mathrm{M}\end{array}$} & \multirow{4}{*}{$\begin{array}{l}18 \mathrm{~F} \\
31 \mathrm{~F} \\
11 \mathrm{~F} \\
10 \mathrm{~F} \\
19 \mathrm{~F}\end{array}$} \\
\hline & & & \\
\hline & & & \\
\hline & & & \\
\hline & 'Tot & $84 \mathrm{M}$ & 89 \\
\hline
\end{tabular}

Another batch of thirty-seven heifers was inseminated in San Francisco in August and September 1965. The semen was allowed to sediment in glass tubes containing medium ' $B$ ', and the bottom fraction was selected after the column had been quickly deep frozen. All the heifers became pregnant, but twenty of them had to be inseminated twice or more with the fractionated semen. The animals were slaughtered after 35-60 days of pregnancy, except for one which was allowed a normal delivery. The sex of the foetus was determined from a macroscopic inspection of the primary sex organs, except for three rejected cases where development was incomplete. As can be seen in Table 1, the sex distribution was again not very far from equality.

Although in these experiments the predictions were not successful, subsequent work has indicated that the techniques used here for differential sedimentation may not be entirely free from disturbing factors, and by applying slightly modified methods Schilling ${ }^{3,4}$ has apparently obtained greater success in predetermining the sex of calves. Further biological tests of the significance of the variation in sedimentation velocity among spermatozoa are clearly needed.

We acknowledge the help of Mr. H. J. Ballinger, who collected and analysed many of the data.
B. C. Bhattacharya*
A. D. BANGHAM
R. J. CRO
R. D. KEYNES

Agricultural Research Council

Institute of Animal Physiology,

Babraham, Cambridge.

Agricultural Research Council

L. E. A. Rowson

Unit of Reproductive Physiology and Biochemistry, Cambridge.

* Present address: S.W.B. Research Corporation, 320 Judah Street, San Francisco, California.

${ }^{1}$ Bhattacharya, B. C., Z. Tierznecht. Zuecht. Biol., 72, 250 (1958).

${ }^{2}$ Bhattacharya, B. C., Z. wiss. Zool., 166, 203 (1962).

${ }^{3}$ Schilling, E., Naturviss., 52, 353 (1965).

4 Schilling, E., J. Reprod. Fert., 11, 469 (1966). 